\title{
Dioxin-Produced Alteration in the Profiles of Fecal and Urinary Metabolomes: A Change in Bile Acids and Its Relevance to Toxicity
}

\author{
Saki Kakizuka, ${ }^{a, \#}$ Tomoki Takeda, ${ }^{a, \#}$ Yukiko Komiya, ${ }^{a}$ Akihiko Koba, ${ }^{a}$ Hiroshi Uchi, ${ }^{b}$ \\ Midori Yamamoto, ${ }^{c}$ Masutaka Furue, ${ }^{b, d}$ Yuji Ishii, ${ }^{a}$ and Hideyuki Yamada, ${ }^{*}$ \\ ${ }^{a}$ Laboratory of Molecular Life Sciences, Graduate School of Pharmaceutical Sciences, Kyushu University; 3-1-1 \\ Maidashi, Higashi-ku, Fukuoka 812-8582, Japan: ${ }^{b}$ Department of Dermatology, Graduate School of Medical

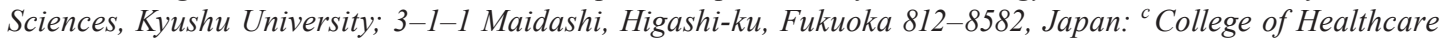 \\ Management; 960-4 Takayanagi, Setaka-cho, Miyama, Fukuoka 835-0018, Japan: and ${ }^{d}$ Research and Clinical \\ Center for Yusho and Dioxin, Kyushu University Hospital; 3-1-1 Maidashi, Higashi-ku, Fukuoka 812-8582, Japan. \\ Received March 15, 2015; accepted June 20, 2015
}

This study investigated dioxin-induced changes in metabolomes in pubertal rat excrement. The administration of 2,3,7,8-tetrachlorodibenzo-p-dioxin (TCDD) or restricting dietary intake (pair-fed group) markedly altered the metabolomic profile including lipids, hormones, and vitamins in the urine and feces. TCDD caused an increase in the fecal chenodeoxycholic acid and taurocholic acid content and in urinary adrenaline and $17 \beta$-estradiol, while the urinary melatonin level was reduced by TCDD. These changes were not observed in the pair-fed group. In accordance with the elevated level of fecal bile acids, TCDD reduced the intestinal expression of the apical sodium-dependent bile salt transporter, which plays a role in resorbing bile acids from the bile duct. In addition, CYP7A1, a rate-limiting enzyme for bile acid biosynthesis, was attenuated by TCDD treatment, although TCDD induced hepatic CYP8B1, an enzyme essential for cholic acid synthesis. Supplying cholic acid or chenodeoxycholic acid to TCDD-exposed rats tended to restore the TCDD-produced reduction in serum triglycerides, whereas no similar trend was observed in wasting syndrome and lipid accumulation in the liver. These results suggest that: 1) TCDD alters the circulating levels of bile acids and hormones via a mechanism distinct from an attenuation in dietary intake, although the majority of TCDDinduced changes in nutrient contents in the excrement is due to a reduction in food intake; and 2) TCDD facilitates the excretion of bile acids and disrupts their biosynthesis, resulting in the disturbance of lipid homeostasis.

Key words 2,3,7,8-tetrachlorodibenzo-p-dioxin; bile acid; metabolome; aryl hydrocarbon receptor

Dioxin and related compounds, one of the prototypic environmental pollutants, are highly persistent in nature and animals, ${ }^{1)}$ and their harmful effects on the health of humans and wildlife have been known for a long time. In laboratory animals, administration of dioxins causes a number of toxic effects, such as wasting syndrome, carcinogenesis, immunosuppression and teratogenic changes. ${ }^{2)}$ It is currently believed that a nuclear receptor, the aryl hydrocarbon receptor (AhR), plays a critical role in causing many, if not all, these effects. $^{3-5)} \mathrm{AhR}$ is activated on binding to a ligand such as dioxin, and migrates to the nucleus. In the nucleus, the AhRligand complex binds to its cognitive sequence, designated as the xenobiotic responsive element (XRE), present in the 5'-upstream region of the target genes such as CYP1A1 causing a change in the expression. ${ }^{6,7)}$ Among more than 200 genes governed by AhR-dependent mechanisms, ${ }^{8)}$ the induction of CYP1A1 is suggested to cause some forms of acute toxicity produced by dioxins. ${ }^{9}$ However, the target genes which give rise to the toxic effects of dioxins have not yet been fully investigated.

A dioxin-dependent change in the expression of genes must influence metabolomic profiles in tissues and body fluids due to the altered expression of functional proteins such as enzymes, transporters and receptors. It is, therefore, likely that such a change in metabolome is directly linked to the toxicity. To address this issue, many researchers have conducted com-

\footnotetext{
\# These authors contributed equally to this work.
}

prehensive metabolomic analyses, the results of which have suggested that dioxins alter the levels of a number of compounds and components in the liver, ${ }^{10-12)}$ skeletal muscle, ${ }^{12)}$ hippocampus, ${ }^{13)}$ cerebellum, ${ }^{14)}$ blood,${ }^{15,16)}$ and urine ${ }^{17)}$ in mice and rats, and in HepG2 cells. ${ }^{18)}$ However, in spite of these research findings, the component(s) contributing to dioxin toxicity appears to remain largely unidentified. Regarding the reproductive and developmental disorders produced by dioxin, our previous studies have revealed that treating pregnant rats with 2,3,7,8-tetrachlorodibenzo- $p$-dioxin (TCDD), the most toxic congener of dioxins, markedly alters the metabolomic pattern including the components of the tricarboxylic acid cycle in the hypothalamus of male fetuses. ${ }^{19,20)}$ In view of the background mentioned above, the initial objective of the present study was to identify the components, the levels of which are changed in a dioxin-specific fashion, in the urine and feces of pubertal rats. It has long been known that TCDD and related substances reduce food consumption in animals ${ }^{21,22)}$ and this may be at least one of the reasons why dioxins produce wasting syndrome exemplified as body weight loss. In addition, as AhR-dependent signaling is suggested to play a role in the regulation of energy production, ${ }^{23,24)}$ an alternative possibility is that acute dioxin toxicity including wasting syndrome arises from the direct action of dioxin on energy-related genes but not from food restriction. Therefore, to understand the contribution of a metabolomic change to dioxin-produced toxicity, it would be useful to distinguish between a change directly induced by dioxin and the outcome secondarily produced 
from food restriction. With this in mind, the present study involved the preparation of another control (pair-fed control) in addition to a simple control. In the former control, diet was limited to the amount which was equivalent to that consumed by TCDD-exposed rats. Then, the metabolomic profile was compared among control, pair-fed control and a TCDD-treated group, using an ultra-performance liquid chromatography-time of flight-mass spectrometry (UPLC-TOF-MS) system. Of the data obtained, we focused on an increase in the fecal level of chenodeoxycholic acid and taurocholic acid. In this context, a previous study using a DNA microarray analysis also suggested that TCDD alters the hepatic expression of genes associated with the metabolism of cholesterol, and the biosynthesis and transport of bile acids. ${ }^{25)}$ As established already, bile acids play an important role in the intestinal absorption of lipids and cholesterol, ${ }^{26-28)}$ steroid metabolism ${ }^{29)}$ and the biliary secretion of lipids and xenobiotics. ${ }^{30)}$ Therefore, an excess of bile acids may be linked to TCDD-produced wasting syndrome and the impaired utilization of lipids. We then investigated this issue and the mechanism underlying a TCDD-produced increase in the fecal content of bile acids.

\section{MATERIALS AND METHODS}

Materials TCDD was purchased from Accu Standard Inc. (New Haven, CT, U.S.A.). Anti-rat CYP1A1 antibody was prepared in this laboratory. Alexa Fluor ${ }^{\circledR} 647$ Conjugate was purchased from Cell Signaling Technology Inc. (Danvers, MA, U.S.A.). All other reagents were of the highest grade commercially available.

Animals and Treatments All animal experiments were pre-approved by the Institutional Animal Care and Experiment Committee of Kyushu University. Male Wistar rats (4 weeks old) were purchased from Kyudo Co., Ltd. (Tosu, Japan). They were kept in a room maintained at $22 \pm 5^{\circ} \mathrm{C}$ and $50 \pm 15 \%$ relative humidity under a $24 \mathrm{~h}$ light/dark cycle (light period, 7:00 a.m.-7:00 p.m.). They were housed individually in metabolic cages, and food and tap water were provided ad libitum. After adaptation for a week, they were treated with a single oral dose of TCDD $(60 \mu \mathrm{g} / \mathrm{kg} / 2 \mathrm{~mL}$ corn oil) or vehicle. Then, pair-fed control rats were given food in an amount which was equivalent to that consumed by the TCDD-treated rats. Their blood and tissues were collected seven days after TCDD treatment. Also, their feces and urine were collected for $24 \mathrm{~h}$ before dissection under euthanasia by inhalation of carbon dioxide. In some experiments, male rats were given $0.25 \%$ cholic acid- or $0.1 \%$ chenodeoxycholic acid-containing water ad libitum during one day before TCDD treatment and the day of dissection.

Reverse Transcription-Polymerase Chain Reaction (RTPCR) The expression of mRNAs was quantified by real-time RT-PCR according to the method described previously. ${ }^{19,31)}$ In brief, total RNA was extracted from the liver and intestine using an RNeasy Mini Kit (QIAGEN GmbH, Hilden, Germany). The RNA (250 ng) obtained was treated with genomic DNA (gDNA) Eraser for digestion of contaminating gDNA, and reverse-transcribed to its cDNA, using a PrimeScript ${ }^{\circledR}$ RT reagent kit (TaKaRa Bio Inc., Shiga, Japan). The cDNAs obtained from target mRNAs were amplified with Fast SYBR Green Master Mix (Life Technologies, Carlsbad, CA, U.S.A.), using a StepOnePlus Real-time PCR system (Life Technolo- gies). The primer sequences are shown in the Supplementary Table 1. The PCR conditions were as follows: $95^{\circ} \mathrm{C}, 20 \mathrm{~s}-40$ cycles $\left(95^{\circ} \mathrm{C}, 3 \mathrm{~s}-60^{\circ} \mathrm{C}, 30 \mathrm{~s}\right)$. The relative level of mRNA was determined using the $2^{-\Delta \mathrm{CT}}$ method. ${ }^{32)}$ The amount of target mRNA was normalized by $\beta$-actin mRNA, and is shown as a ratio to the control.

Metabolomics Fecal components were extracted by a reported method. ${ }^{33)}$ In brief, the feces were dried in a desiccator with silica gel for one week, and powdered in a mortar. A portion $(0.1 \mathrm{~g})$ of this was mixed vigorously for $5 \mathrm{~min}$ with six volumes of $50 \%$ methanol containing glycylnorleucine $(0.5 \mu \mathrm{g} / \mathrm{mL})$ and nonanoic acid $(0.1 \mu \mathrm{g} / \mathrm{mL})$ as internal standards. After centrifugation at $1000 \times \boldsymbol{g}$ for $10 \mathrm{~min}$, the pellets were again extracted with three volumes of methanol. Both supernatants were mixed, and the solvent was evaporated using a vacuum concentrator (CVE-3100; Tokyo Rikakikai, Co., Ltd., Tokyo, Japan). The extract obtained was dissolved in $10 \%$ methanol at a concentration of $2.5 \mu \mathrm{L} / \mathrm{mg}$ feces. Urine was also extracted using the reported method. ${ }^{33)}$ For example, $5 \mathrm{mg}$ sodium azide was added to the urine, and this sample was filtered by passage through a cotton plug. The filtrate obtained was diluted with $\mathrm{H}_{2} \mathrm{O}$ to $30 \mathrm{~mL}$, and the supernatant obtained by centrifugation at $1500 \times \mathbf{g}$ for $15 \mathrm{~min}$ was used for the metabolomic study. A portion $(10 \mu \mathrm{L})$ of all samples was subjected to a UPLC-TOF-MS system (LCT-Premier XE Waters, Milford, MA, U.S.A.) for metabolomic analysis.

The operating conditions of LC were as follows: column: HSS T3 column $(2.1 \times 100 \mathrm{~mm}, 1.8 \mathrm{~mm}$ i.d., Waters $)$; column temperature: $40^{\circ} \mathrm{C}$; sample room temperature: $4^{\circ} \mathrm{C}$ (urine) and $10^{\circ} \mathrm{C}$ (feces); mobile phase: A: $0.1 \%$ formic acid (positive ion mode) or $10 \mathrm{~mm} 4$-methylmorphorin (negative ion mode), and B: methanol (urine) or acetonitrile (feces); elution program [\% of $\mathrm{B}$ in A (min)]: $0 \%(0-5), 0$ to $40 \%(5-20), 40$ to $90 \%$ (20-29), 90\% (29-30), 90 to $0 \%(30-31)$ and $0 \%(31-35)$; flow rate, $0.2 \mathrm{~mL} / \mathrm{min}$.

The conditions of TOF-MS were as follows: ionization mode: electrospray; capillary voltage: $3 \mathrm{kV}$ in positive ion mode and $-2.5 \mathrm{kV}$ in negative ion mode; sample cone voltage: $50 \mathrm{~V}$; source temperature: $120^{\circ} \mathrm{C}$; and flow rate of cone gas: $50 \mathrm{~L} / \mathrm{h}$. The desolvation was conducted at $350^{\circ} \mathrm{C}$ with a nitrogen flow rate of $600 \mathrm{~L} / \mathrm{h}$. Leucine-enkepharin was used as a reference for lockmass correction.

All metabolomic data were processed using MarkerLynx ${ }^{\mathrm{TM}}$ XS software (Waters). Firstly, the data matrix from individual rats was subjected to a principal component analysis (PCA). To compare metabolomic profiles between the control and TCDD-treated group or between the control and pair-fed group, the data compiled in MarkerLynx ${ }^{\mathrm{TM}} \mathrm{XS}$ was then analyzed by an orthogonal partial least square to latent structuresdiscriminant analysis (OPLS-DA) method. ${ }^{34)}$ From the S-plot obtained, fragment ions with correlation co-efficients of more than +0.8 and less than -0.8 were extracted as significantlyincreased and -decreased ions by TCDD or pair-fed treatment, respectively. Then, the components changed by TCDD and pair-feeding were estimated by referring the retention time and mass information of the ions to online databases including the Human Metabolome Database (http://www.hmdb.ca/) and the Kyoto Encyclopedia of Gene and Genomes (KEGG, http:// www.genome.jp/).

Determination of Bile Acids The levels of bile acids in the feces and liver were determined by UPLC-TOF-MS ac- 

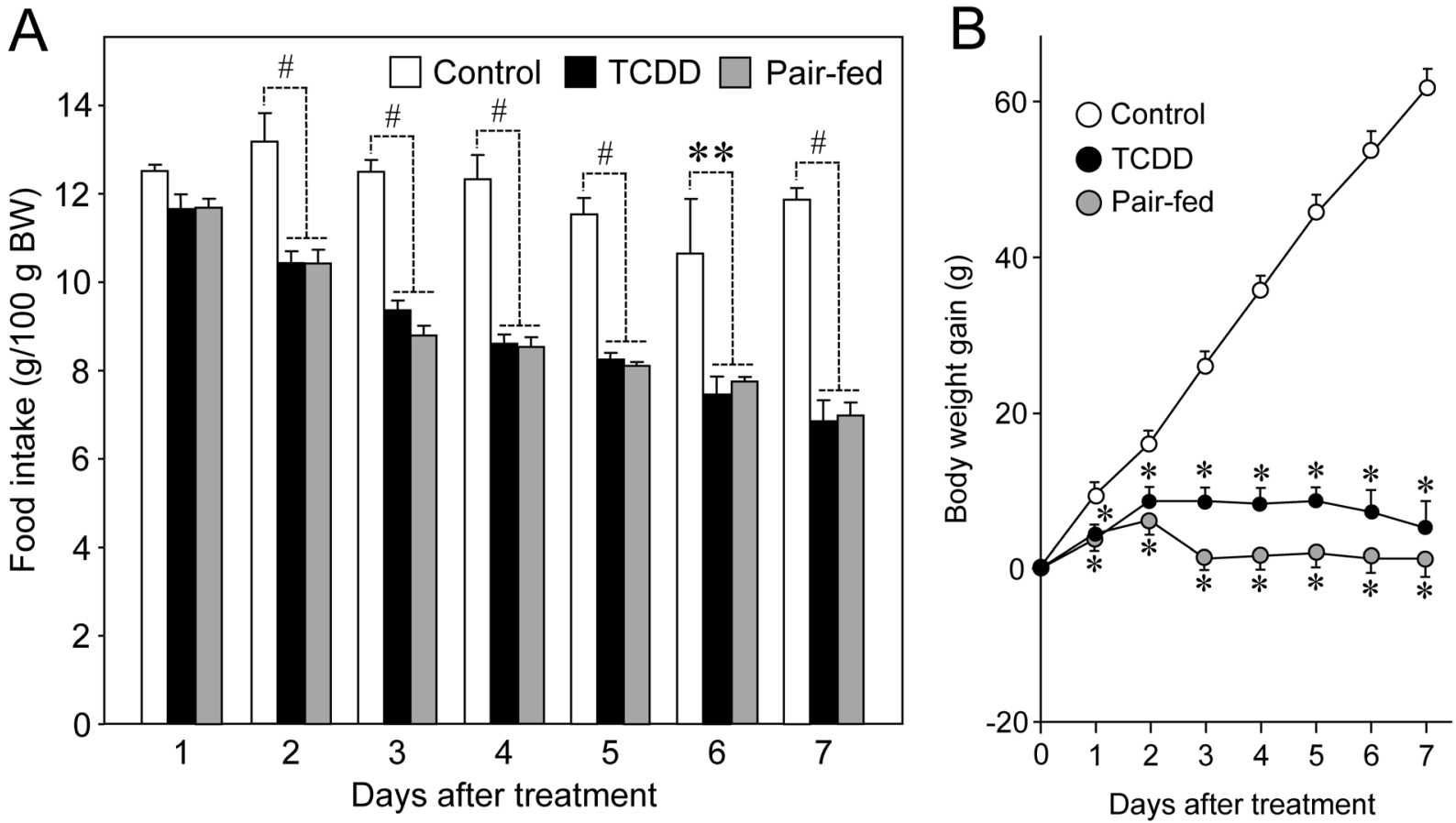

Fig. 1. Effect of TCDD and Food Restriction on the Amount of Food Intake (A) and Body Weight Gain (B)

The bars/plots represent the means \pm S.E.M. of $4-16$ rats. Significantly different from the control: ${ }^{*} p<0.05,{ }^{*} p<0.01$ and ${ }^{*} p<0.001$

cording to the published method ${ }^{35)}$ with some modifications. The liver was homogenized in four volumes of $50 \mathrm{~mm}$ Tris$\mathrm{HCl}(\mathrm{pH} 7.4)$. Powdered feces $(50 \mathrm{mg}$ ) and hepatic homogenate $(250 \mu \mathrm{L})$ were mixed, respectively, with $50 \mathrm{~mm}$ sodium acetate $(\mathrm{pH} 5.2,0.5 \mathrm{~mL})$ and $99.5 \%$ ethanol $(1.5 \mathrm{~mL})$ containing $0.5 \mu \mathrm{g}$ dexamethasone, an internal standard, and incubated for $60 \mathrm{~min}$ at room temperature. Three volumes of water were added to the supernatant obtained by centrifugation at $2000 \times \boldsymbol{g}$ for $10 \mathrm{~min}$, and this mixture was then applied to a Bond Elut C18 cartridge $(500 \mathrm{mg} / 6 \mathrm{~mL}$; Agilent Technologies Inc., Santa Clara, CA, U.S.A.). After washing the cartridge with $25 \%$ ethanol, bile acids were eluted with $5 \mathrm{~mL}$ of $99.5 \%$ ethanol. The solvent of the elute was evaporated using a vacuum concentrator (Tokyo Rikakikai, Tokyo, Japan), and the residue obtained was dissolved in $50 \%$ ethanol at a concentration of $2 \mu \mathrm{L} / \mathrm{mg}$ feces and liver. A portion $(10 \mu \mathrm{L})$ of these samples was subjected to a UPLC-TOF-MS system, and the instrument was operated in negative ion mode under the same conditions as those used in metabolomic analysis. The LC conditions were as follows; column: $\mathrm{BEH} \mathrm{C} 18$ column $(2.1 \times 100 \mathrm{~mm}$, $1.8 \mathrm{~mm}$ i.d., Waters); mobile phase: mixed solvents consisting of $5 \mathrm{~mm}$ ammonium acetate (A) and methanol (B); elution program [\% of B in A (min)]: 20\% (0-3.1), 20 to 98\% (3.1-30), $98 \%(30-35), 98$ to $20 \%(35-36)$ and $20 \%$ (36-40); and flow rate, $0.2 \mathrm{~mL} / \mathrm{min}$.

Histopathological Examination and Immunofluorescence Liver was fixed in $4 \%$ paraformaldehyde, embedded in Tissue-Tek ${ }^{\circledR}$ OCT compound (Sakura Finetechnical Co., Ltd., Tokyo, Japan), and frozen in 2-methylbutane $\left(-80^{\circ} \mathrm{C}\right)$. The frozen liver was sliced into sections with a thickness of $10 \mu \mathrm{m}$ using a microtome (CM3050S; Leica microsystems, Wetzlar, Germany), and each section was mounted on a glass slide. The lipid accumulation in the liver was analyzed by oil red-O staining. ${ }^{36)}$ More specifically, the mounted tissues were stained with $0.18 \%$ oil red-O in $60 \%$ 2-propanol for $30 \mathrm{~min}$ at room temperature, and washed with 60\% 2-propanol and water. Then, the cryosections were immersed in $0.2 \%$ hematoxylin for $1 \mathrm{~min}$ to counterstain the nucleus, and observed using an optical microscope (CX-41; Olympus Corp., Tokyo, Japan).

For detection of hepatic CYP1A1, the liver section mounted on a slide glass was washed twice with phosphate-buffered saline (PBS) containing $10 \mathrm{~mm}$ glycine, and incubated in PBS containing $3 \%$ bovine serum albumin for $30 \mathrm{~min}$ at $37^{\circ} \mathrm{C}$. After washing twice with $10 \mathrm{~mm}$ glycine-PBS, the cryosection was incubated overnight with anti-rat CYP1A1 antibody. Then, the section was washed six times with PBS containing $0.05 \%$ Tween 20, and treated with Alexa Fluor ${ }^{\circledR}$ 647-conjugated secondary antibody and 4',6'-diamino-2-phenylindole for $40 \mathrm{~min}$ at $37^{\circ} \mathrm{C}$. After washing six times with $0.05 \%$ Tween $20-\mathrm{PBS}$, the section was mounted in $90 \%$ glycerol containing $0.1 \% p$-phenylenediamine, and subjected to analysis by confocal microscopy (LSM700; Carl Zeiss, Jena, Germany).

Other Methods Serum and hepatic levels of triglycerides, cholesterol, and free fatty acids were measured on the basis of established color reactions using commercial kits (Wako Pure Chemical Industries, Ltd., Osaka, Japan). The statistical difference between two groups was compared by Student's $t$-test. In the comparison among multiple groups, statistical differences were calculated by one-way analysis of variance with a post-hoc test (Turkey's test) using Excel Statistics 2010 software (Social Survey Research Information Co., Ltd., Tokyo, Japan). The statistical significance was set at $p<0.05$.

\section{RESULTS}

Effect of TCDD or Restriction of Food Intake on the Body and Tissue Weight of Male Pubertal Rats In accordance with previous reports, ${ }^{21,22)}$ oral administration of TCDD reduced daily food intake starting two days after treatment (Fig. 1A). In addition, TCDD caused the suppression of body 

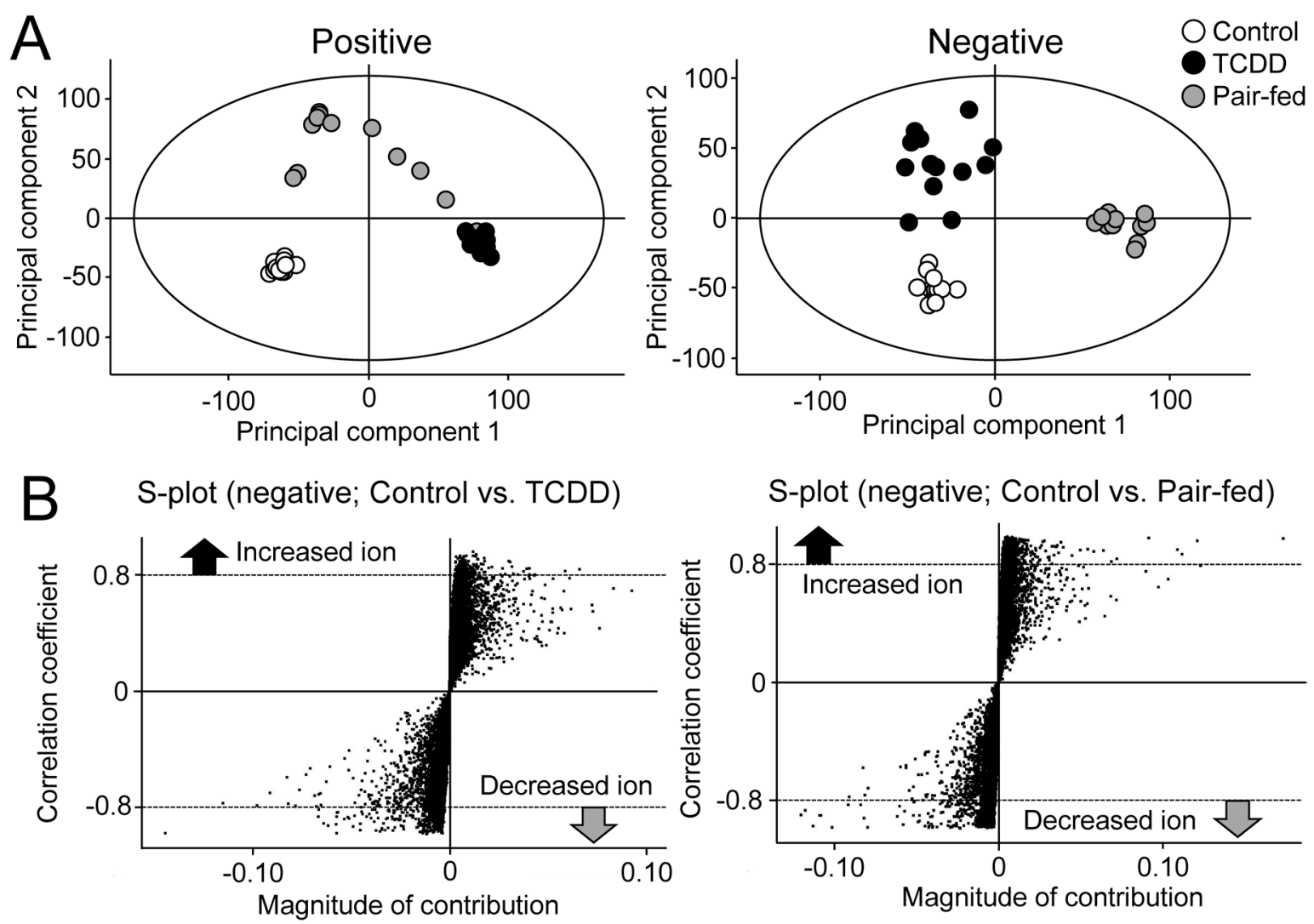

Fig. 2. Principal Component Analysis of a Change in the Profile of Urinary Metabolome by TCDD and Food Restriction

Male pubertal rats were exposed either to TCDD $(60 \mu \mathrm{g} / \mathrm{kg}$, p.o.) or vehicle alone (each $N=12)$, and their metabolomic profile in the urine was analyzed. Panel A represents the Score plot of the control, TCDD and pair-fed group. B is the S-plot analyzed by negative ion mode between the control and TCDD group (left) and the control and pair-fed group (right).

weight gain (Fig. 1B), hepatomegaly, and atrophy of the thymus and spleen (Supplementary Fig. 1). Restricting the food intake to a level equivalent to that consumed by TCDD-treated rats not only reduced the body weight gain (Fig. 1B) but also the slightly atrophied thymus and spleen (Supplementary Fig. 1). However, in contrast to TCDD treatment, food restriction caused a decrease rather than an increase in liver weight (Supplementary Fig. 1). These results suggest that restriction of food intake also alters the tissue weight as well as the body weight like TCDD, although their patterns of change were not identical.

Effect of TCDD or Food Restriction on Metabolomic Profiles in Excrement To investigate the contribution of a TCDD-induced reduction in food intake to a change in metabolomic profile, polar metabolites extracted from excrement were subjected to UPLC-TOF-MS analysis. The Score plot obtained from the PCA analysis of the urine and feces showed that each cluster of plots in the three treatment groups were clearly separated from each other (Figs. 2A, 3A). In agreement with this, further analysis using the OPLS method suggested that, in the feces and urine, the majority $(\geqq 1 / 2)$ of metabolomic changes caused by TCDD did not overlap with those produced by food restriction (Figs. 2B, 3B, Tables 1, 2). For example, while the urinary content of melatonin and norepinephrine was reduced by TCDD treatment, TCDD reversely increased fecal melatonin and adrenaline and $17 \beta$-estradiol in the urine (Table 1). In addition, the fecal levels of chenodeoxycholic acid and taurocholic acid were increased only by TCDD treatment (Tables 1,2). A change in these bile acids was verified by fine determination (Fig. 4), and this analysis also found an increase in glycochenodeoxycholic acid in the feces of TCDD-exposed rats (Fig. 4). These results suggest that, although part of the TCDD-produced alteration in the metabolome of excrement is due to a reduction in food intake, many changes including those of hormones and bile acids are caused through mechanisms distinct from reducing food intake.

Effect of TCDD on the Expression of Bile AcidSynthesizing Enzymes and Transporters To explore the mechanism whereby TCDD increases the fecal content of bile acids, we analyzed the expression of mRNAs coding for bile acid-synthesizing and -conjugating enzymes and transporters. In agreement with the elevated excretion of bile acids, TCDD reduced the intestinal expression of apical sodium-dependent bile salt transporter (ASBT), a re-absorbing transporter from the bile duct to the small intestine (Fig. 5A). However, the hepatic transporters involved in the excretion of bile acids to the bile duct, i.e., multidrug resistance-associated protein 2 (MRP2) and bile salt export pump (BSEP), were resistant to TCDD treatment (Fig. 5B). Cofusingly, while TCDD reduced the hepatic expression of CYP7A1, a rate-limiting enzyme for bile acid synthesis, CYP8B1, an enzyme necessary for the synthesis of cholic acid, was induced by dioxin (Fig. 5B). The same did not occur by restricting food intake, although CYP27A1 was induced by the treatment (Fig. 5B). A hepatic transporter, $\mathrm{Na}^{+} /$taurocholate co-transporting polypeptide (NTCP), importing cholates from the portal vein, tended to be reduced by TCDD treatment (Fig. 5B). However, TCDD did 


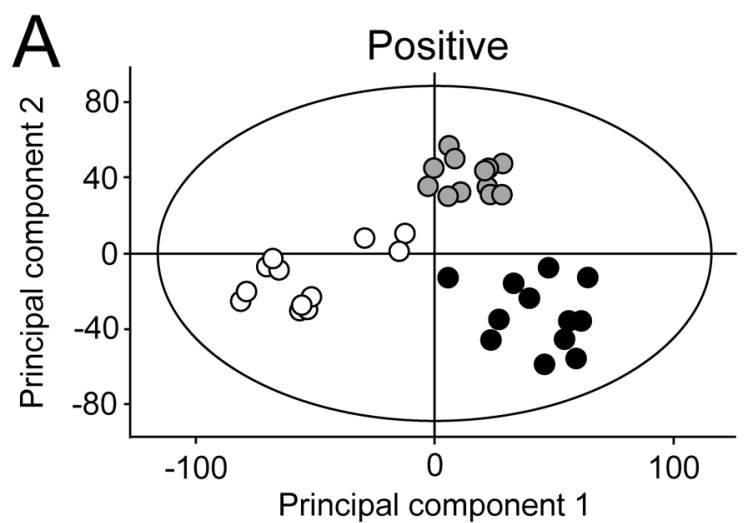

B S-plot (negative; Control vs. TCDD)

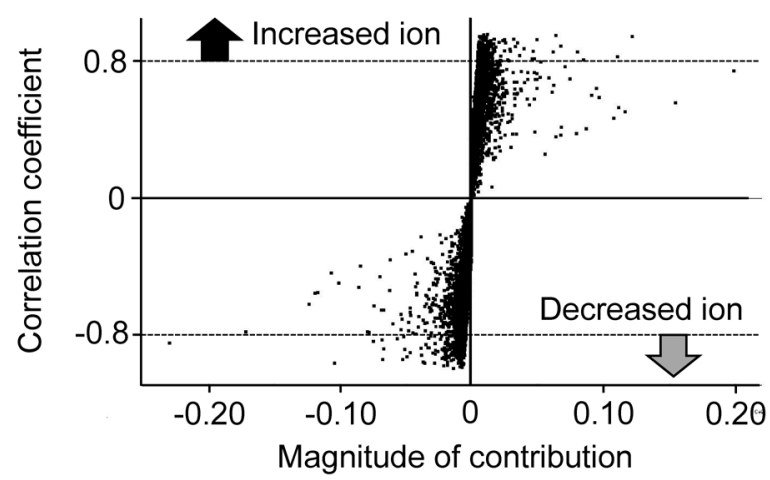

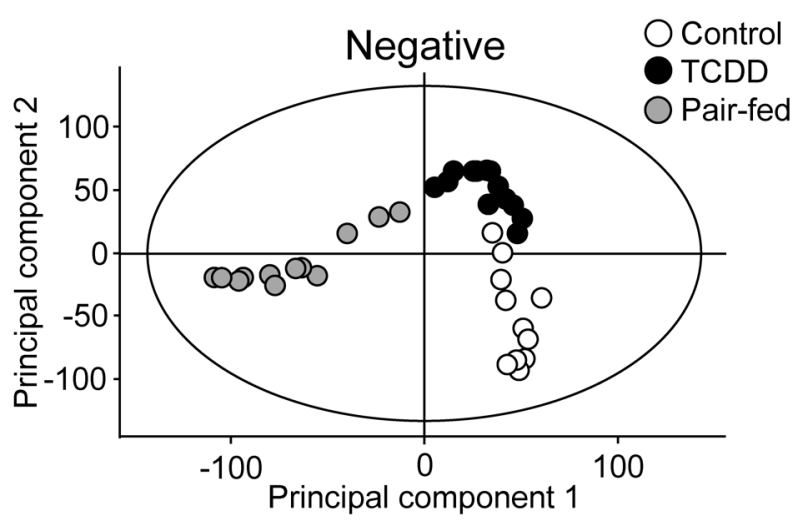

S-plot (negative; Control vs. Pair-fed)

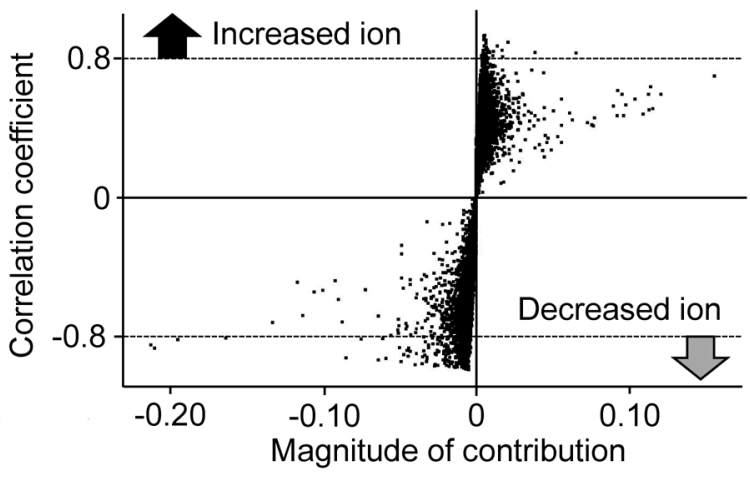

Fig. 3. Principal Component Analysis of a Change in the Profile of Fecal Metabolome by TCDD and Food Restriction

Male pubertal rats were exposed either to TCDD $(60 \mu \mathrm{g} / \mathrm{kg}$, p.o.) or vehicle alone (each $N=12)$, and their metabolomic profile in the feces was analyzed. Panel A represents the Score plot of the control, TCDD and pair-fed group. B is the S-plot analyzed by negative ion mode between the control and TCDD group (left) and the control and pair-fed group (right).

not alter the intestinal expression of organic solute transporter (OST), a bile acid transporter from the small intestine to the portal vein (Fig. 5A). In accordance with the induction of CYP8B1, TCDD reduced the expression of negative regulators of bile acid synthesis: i.e., farnesoid X receptor (FXR) and its downstream factor, small heterodimer partner (SHP). Liver receptor homologue-1 (LRH-1), one of the transcription factors for CYP8B1 and CYP7A1, was induced by TCDD treatment (Supplementary Fig. 2) while another transcription factor for CYP7A1, hepatocyte nuclear factor $4 \alpha(\mathrm{HNF} 4 \alpha)$, was insensitive to TCDD treatment (Supplementary Fig. 2). TCDD did not cause any significant change in the hepatic expression of bile acid-conjugating enzymes, bile acid CoA: amino acid Nacyltransferase (BAAT) and solute carrier family 27 member 5 (SLC27A5) (Supplementary Fig. 2). These results suggest that TCDD disrupts bile acid homeostasis in a complex manner including altered production and transportation.

Effect of Supplying Bile Acids on TCDD-Produced Acute Toxicity As mentioned above, it is suggested that TCDD facilitates the fecal excretion of cholates and disrupts their synthesis independently of the reduced food consumption. We then assessed whether this change results in a reduction in the body level of cholates. The result indicated that TCDD reduced or tended to reduce the hepatic levels of bile acid (Supplementary Fig. 3), showing an inverse correlation with the fecal levels. For a long time it has been known that cholates play a pivotal role in lipid utilization and excretion. ${ }^{26-30)}$ It is, therefore, conceivable that the reduced level of cholates contributes to TCDD-induced toxicity. To investigate this hypothesis, bile acid-containing drinking water was given to TCDD-exposed rats. This treatment restored or tended to restore the TCDD-induced reduction in bile acids (Supplementary Fig. 3). A reduction by TCDD in the expression of CYP7A1 mRNA was deteriorated by cholic acid and chenodeoxycholic acid (Supplementary Fig. 4). However, the effect of these bile acids differed markedly toward CYP8B1 mRNA; for instance, while cholic acid reduced it to a level below the control rather than abolishing the TCDD effect, chenodeoxycholic acid had little effect on TCDD-produced induction of this mRNA (Supplementary Fig. 4). The TCDD-produced body weight loss, hepatomegaly, and thymic atrophy did not change significantly following bile acid supplementation (Fig. 6). However, the loss in body weight produced by TCDD tended to become severe by co-treatment with bile acids (Fig. 6). Neither chenodeoxycholic acid nor cholic acid seemingly restored TCDD-produced lipid accumulation and CYP1A1 induction (Fig. 7). However, a TCDD-produced increase in the hepatic level of triglycerides tended to recover following the supply of bile acids (Fig. 8A). In accordance with this, a reduction in their circulating level tended to be restored by supplying bile acids (Fig. 8C). The hepatic and serum level of cholesterol was also increased by TCDD treatment, and cholic acid co-treatment promoted this change (Figs. 8B, D). Free fatty acids did not exhibit any change even following both treatments with TCDD and bile acids (Fig. 8E). These results suggest that TCDD alters bile acid homeostasis and then the 
Table 1. Representative Components, the Levels of Which Were Altered by TCDD Treatment, in the Urine and Feces of Male Pubertal Rats

\begin{tabular}{|c|c|c|c|c|}
\hline \multirow{3}{*}{ Sample } & \multicolumn{4}{|c|}{ Representative components altered by TCDD } \\
\hline & \multicolumn{2}{|c|}{ Increased } & \multicolumn{2}{|c|}{ Reduced } \\
\hline & $\geqq 10$ times & $<10$ times & $>1 / 10$ & $\leqq 1 / 10$ \\
\hline \multirow[t]{10}{*}{ Urine } & Adrenaline & $\underline{\text { 4-Pyridoxate }}$ & 5-OH-Tryptophan & Melatonin \\
\hline & Estradiol-17 $\beta$ & LTA4 & 5-Methoxy-L-tryptophan & L-Kynurenine \\
\hline & Capric acid & Lauric acid & $\underline{\text { Pyridoxamine }}$ & Metanephrine \\
\hline & 2-Oxoadipate & cAMP & Arginine & 2-OH-estradiol-17 $\beta$ \\
\hline & & Indoleacetaldehyde & 1-Methyladenosine & $\underline{\text { 6-OH-melatonin }}$ \\
\hline & & & 1-Methylguanine & Noradrenaline \\
\hline & & & & $\underline{\text { Pyridoxal }}$ \\
\hline & & & & $\underline{\text { Riboflavin }}$ \\
\hline & & & & Estrone \\
\hline & & & & Tyrosine \\
\hline \multirow[t]{5}{*}{ Feces } & Chenodeoxycholic acid & Estradiol-17 $\beta$ & $\underline{\text { Cholic acid }}$ & $\underline{\text { Citrate }}$ \\
\hline & Taurocholic acid & Pyridoxamine & $\underline{\text { trans-Retinol }}$ & $\underline{\text { Histidine }}$ \\
\hline & $\underline{\text { Adrenaline }}$ & $\underline{\text { Palmitic acid }}$ & $\underline{\text { Palmitoleic acid }}$ & Capric acid \\
\hline & Melatonin & $\underline{\text { Pyridoxal }}$ & Psychosine & 6-Keto-PGF $1 \alpha$ \\
\hline & Glucose-6-phosphate & Indoleacetaldehyde & & $\alpha$-Tocopherol \\
\hline
\end{tabular}

Underline represents as the components altered by both TCDD and pair-fed treatment. Abbreviations used: PG; prostaglandin, LT; leukotriene.

Table 2. Representative Components, the Levels of Which are Altered by Pair-Fed Treatment, in the Urine and Feces of Male Pubertal Rats

\begin{tabular}{|c|c|c|c|c|}
\hline \multirow{3}{*}{ Sample } & \multicolumn{4}{|c|}{ Representative components altered by TCDD } \\
\hline & \multicolumn{2}{|c|}{ Increased } & \multicolumn{2}{|c|}{ Reduced } \\
\hline & $\geqq 10$ times & $<10$ times & $>1 / 10$ & $\leqq 1 / 10$ \\
\hline \multirow[t]{10}{*}{ Urine } & 20-OH-LTB4 & 5-OH-Tryptophan & 6-OH-Melatonin & Adrenaline \\
\hline & Glycerophosphocholine & 4-Pyridoxate & 5-Methoxy-L-tryptophan & LTA4 \\
\hline & & Melatonin & Arginine & L-Kynurenine \\
\hline & & Taurine & Deoxycytidine & $\overline{\text { Metanephrine }}$ \\
\hline & & 20-COOH-LTB4 & $\underline{\text { Pyridoxal }}$ & Estradiol-17 $\beta$ \\
\hline & & PGE3 & Deoxyadenosine & Estrone \\
\hline & & & Lauric acid & Indoleacetaldehyde \\
\hline & & & & $\underline{\text { Riboflavin }}$ \\
\hline & & & & Tyrosine \\
\hline & & & & Pyridoxamine \\
\hline \multirow[t]{6}{*}{ Feces } & Glucose-6-phosphate & Adrenaline & Cholic acid & Chenodeoxycholic acid \\
\hline & Pyridoxal & 6-OH-Melatonin & Melatonin & $\underline{\text { Histidine }}$ \\
\hline & Capric acid & 6-Keto-PGF1 $\alpha$ & Estradiol-17 $\beta$ & trans-Retinol \\
\hline & Palmitoleic acid & & Pyridoxamine & Homoserine \\
\hline & $16 \alpha$-OH-estrone & & Adenine & Citrate \\
\hline & Palmitic acid & & Palmitoleic acid & \\
\hline
\end{tabular}

Underline represents as the components altered by both TCDD and pair-fed treatment.

lipid status, but this is not a major mechanism for some forms of dioxin toxicity such as wasting syndrome.

\section{DISCUSSION}

The results of this study show that TCDD causes a number of metabolomic changes in the excrement of male pubertal rats, and similar changes were also caused by restricting the food intake to the same level as that consumed by TCDDexposed rats. Also, TCDD changed the urinary and fecal content of some hormones and their metabolites, and increased the fecal level of several bile acids, while the same was not observed in the pair-fed group. Supplying primary bile acids, cholic acid or chenodeoxycholic acid, tended to restore the TCDD-produced reduction in the circulating level of triglycerides, while suppression of body weight, hepatomegaly, thymic atrophy and hepatic accumulation of lipid droplets were not affected by this treatment. These results suggest that: 1) while the majority of TCDD-induced changes in nutrients in the excrement is due to a reduction in food intake, TCDD alters the circulating levels of hormones and bile acids via a mechanism(s) distinct from reducing food intake, and 2) the elevated excretion of bile acids, at least partly, contributes the disruption of lipid homeostasis.

Both TCDD and a reduced food intake caused atrophy of the thymus and spleen in addition to suppression of 

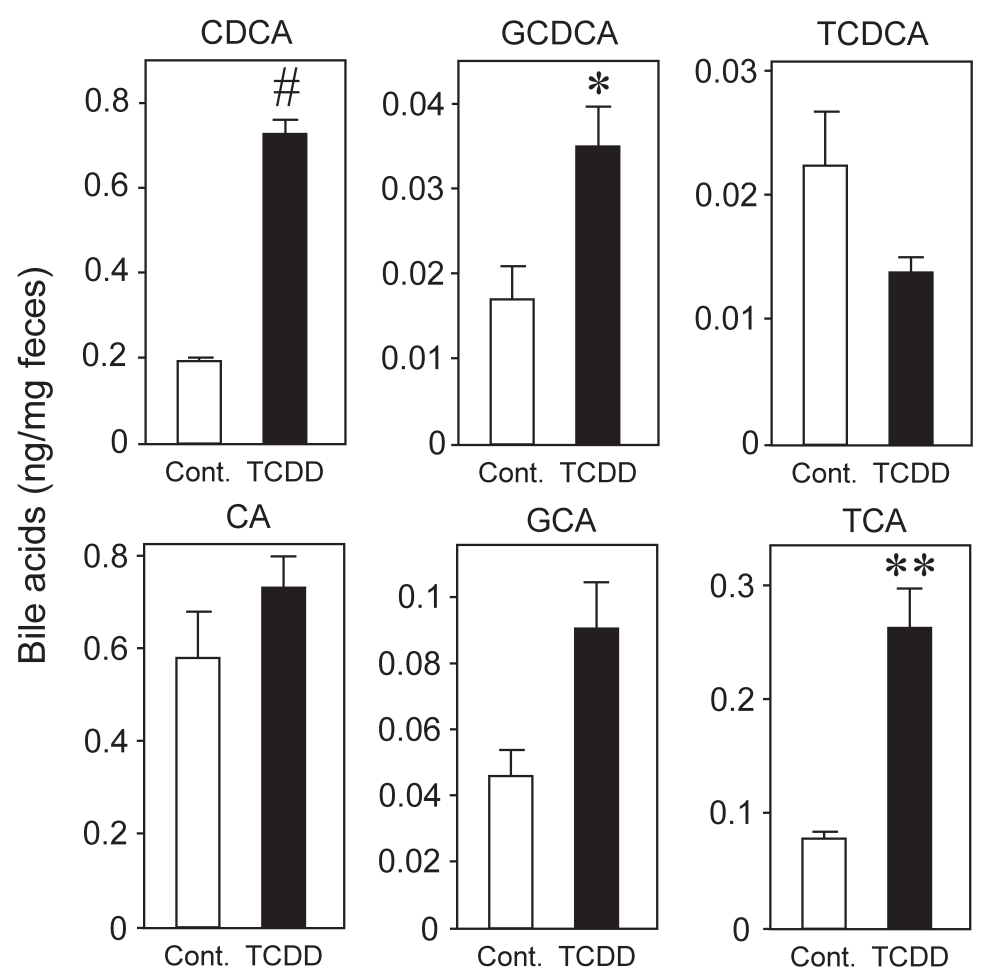

Fig. 4. Effect of TCDD on the Level of Bile Acids in the Feces

Each bar represents the mean \pm S.E.M. of 3-5 rats. Significantly different from the control: $* p<0.05, * * p<0.01$ and ${ }^{\sharp} p<0.001$. Abbreviations used: CDCA, chenodeoxycholic acid; GCDCA, glycochenodeoxycholic acid; TCDCA, taurochenodeoxycholic acid; CA, cholic acid; GCA, glycocholic acid; TCA, taurocholic acid.
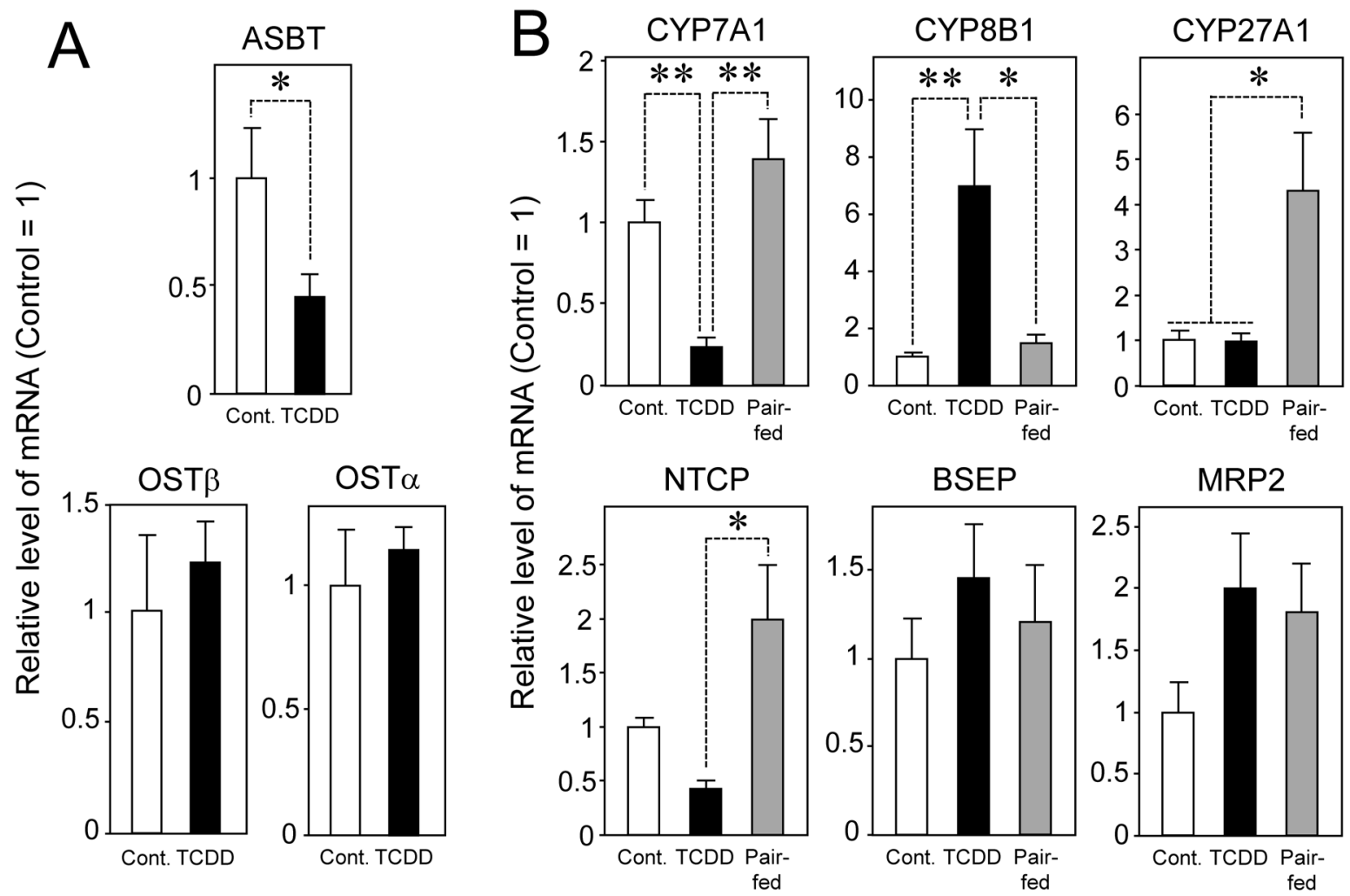

Fig. 5. Effect of TCDD and Food Restriction on the Expression of mRNA Coding for Bile Acid-Synthesizing Enzymes and Transporters in the Small Intestine (A) and Liver (B)

The relative levels of mRNAs were analyzed by real-time RT-PCR, and normalized by $\beta$-actin mRNA. Each bar represents the mean \pm S.E.M. of $5-6$ rats. Significantly different between the pair indicated: $* p<0.05$ and $* * p<0.01$. The control levels of mRNAs $(\%$ of $\beta$-actin; mean + S.E.M., $N=5-6)$ were as follows: ASBT $(0.05 \pm 0.01)$, OST $\alpha$ (3.18 \pm 0.71$)$, OST $\beta$ (1.28 \pm 0.23$)$, CYP7A1 (1.28 \pm 0.18$)$, CYP8B1 (11.0 \pm 1.4$),$ CYP27A1 (34.4 \pm 6.2$),$ NTCP (42.3 \pm 3.3$)$, BSEP (15.0 \pm 4.7$)$ and MRP2 (22.0 \pm 5.3$)$. 

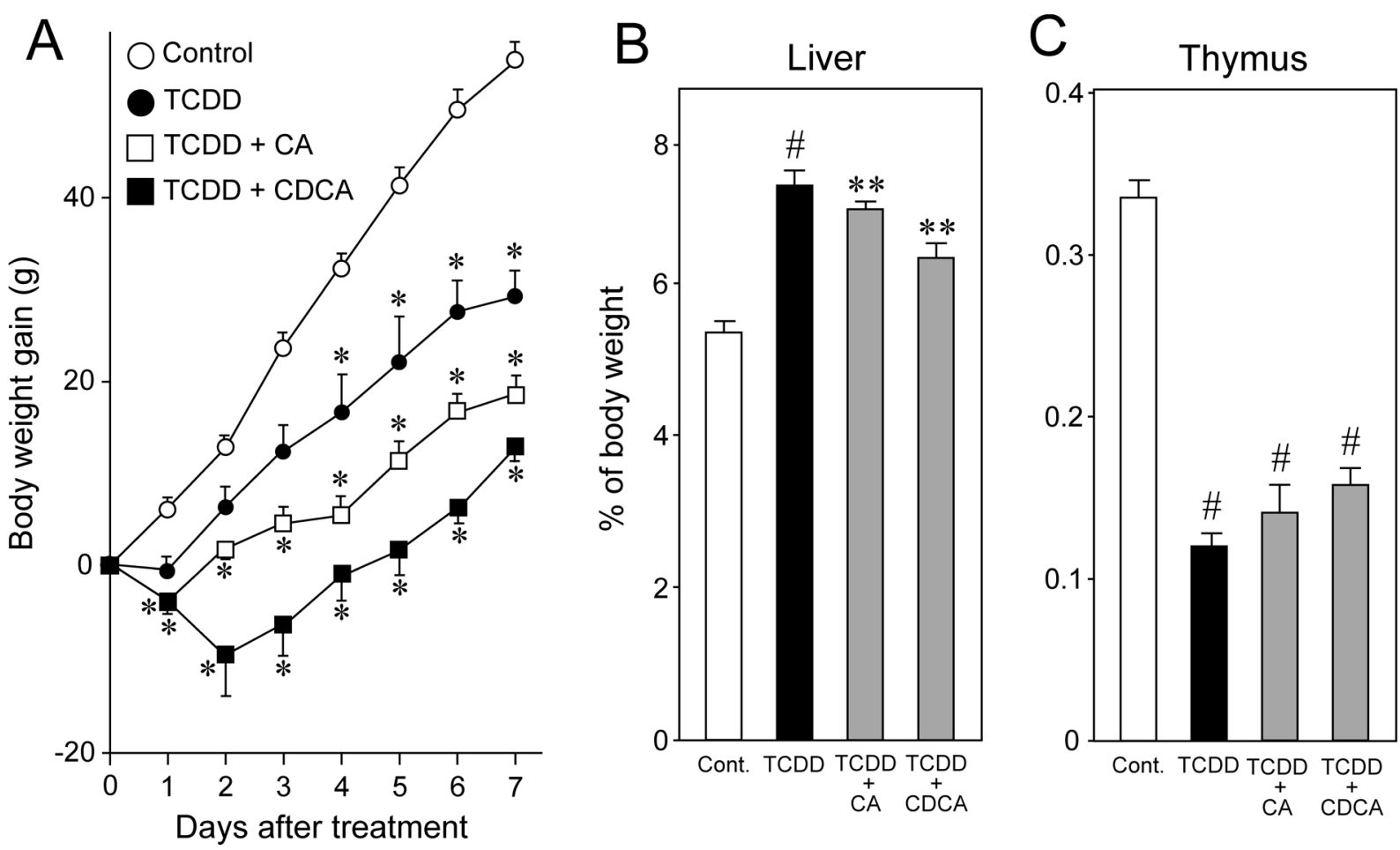

Fig. 6. Absence of the Effect of Bile Acid Supplementation on Body Weight Loss (A), Hepatomegaly (B) and Thymic Atrophy (C) Caused by TCDD The rats were given water containing $0.25 \%$ cholic acid (CA) or $0.1 \%$ chenodeoxycholic acid (CDCA) from one day before TCDD treatment. After treatment with TCDD $(60 \mu \mathrm{g} / \mathrm{kg}$, p.o. $)$ or vehicle alone, the daily body weight and the weight of liver and thymus at $7 \mathrm{~d}$ after treatment were measured. Each plot $/$ bar represents the mean \pm S.E.M. of 5 rats. Significantly different from the control: ${ }^{*} p<0.05, * * p<0.01$ and ${ }^{*} p<0.001$.
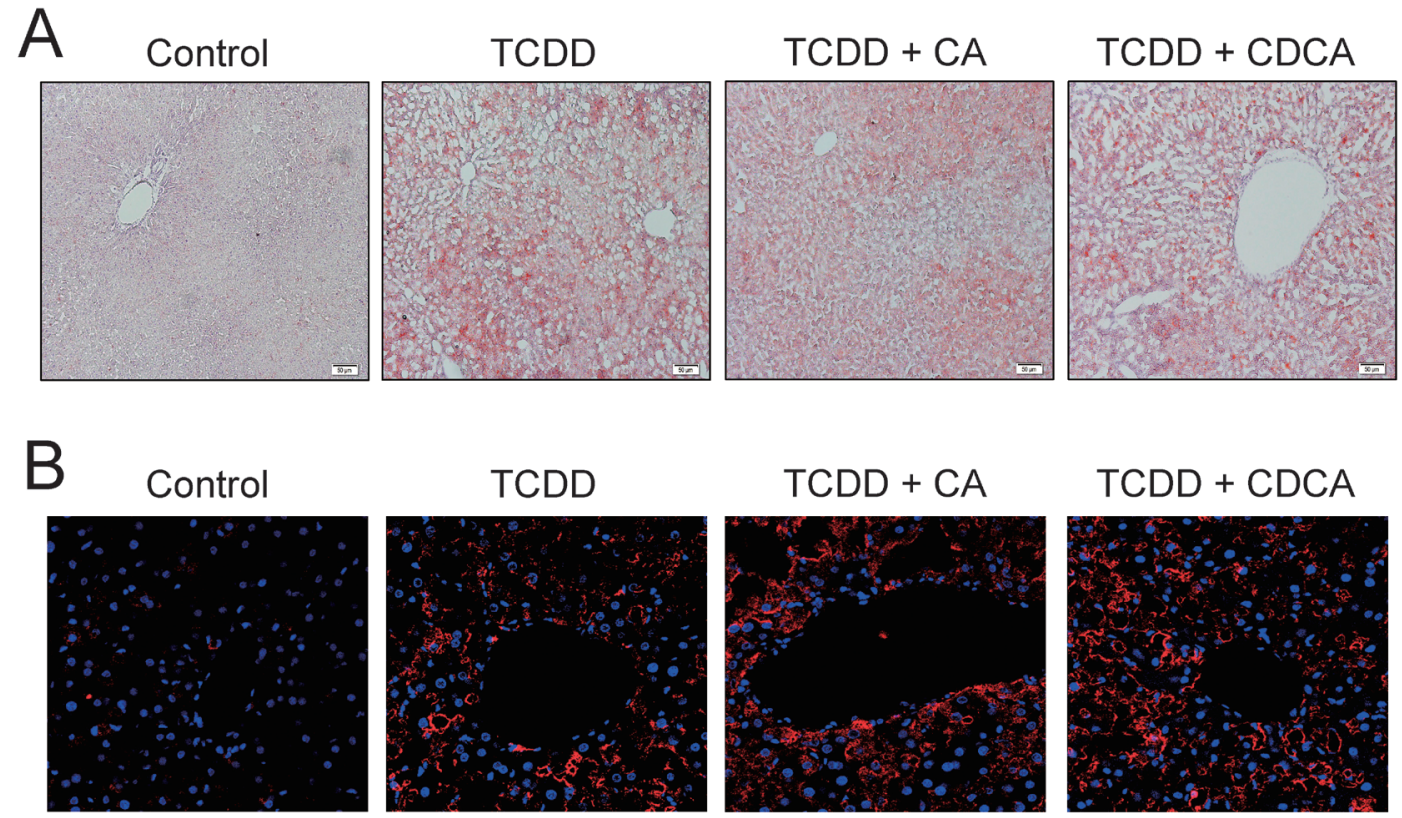

Fig. 7. Absence of the Effect of Bile Acid Supplementation on the TCDD-Produced Accumulation of Lipid Droplets (A) and Induction of CYP1A1 Expression (B) in the Liver of Male Pubertal Rats

A. Hepatic lipids were detected by oil red O staining. B. Tissue sections were stained with anti-rat CYP1A1 (red) and 4',6'-diamino-2-phenylindole (blue).

body weight gain. Taken together with the similarity of the change in metabolome between TCDD and pair-fed groups, it is likely that TCDD produces significant toxicity owing to metabolomic changes based on a reduction in food consumption. However, TCDD-produced hepatomegaly did not occur in the pair-fed group. Although it has been established that dioxin-produced hepatotoxicity occurs via an AhR-governed mechanism, ${ }^{3-5)}$ knocking-out of AhR results in atrophy and dysfunction of the liver even in the absence of dioxin treatment. ${ }^{3-5,37)}$ Thus, it is likely that the endogenous activation of AhR is important for the maintenance of hepatic function and morphology. ${ }^{3-5,37)}$ This study suggests that restricting food intake alters the levels of tryptophan metabolites including a reduction in urinary excretion of L-kynurenine which is a 

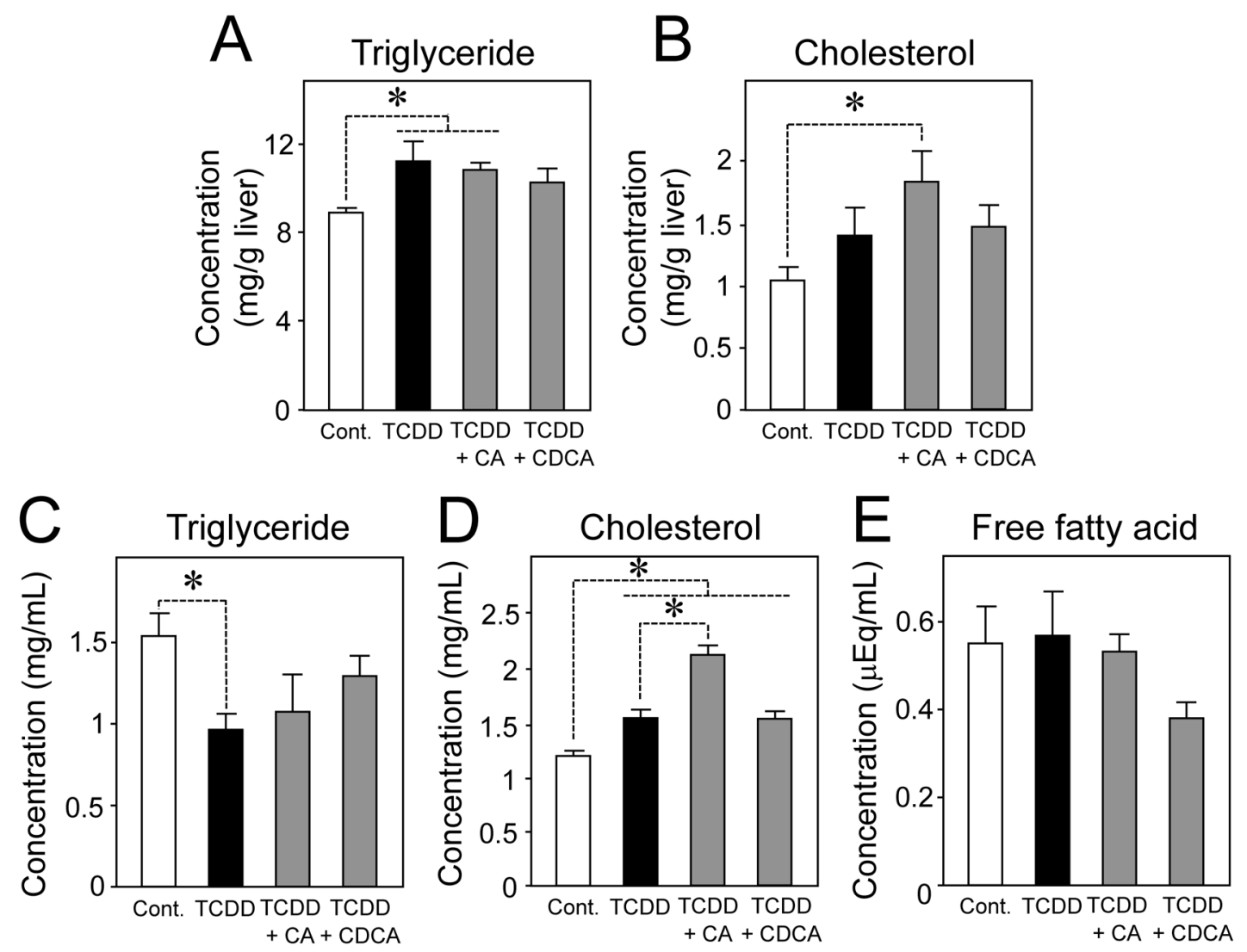

Fig. 8. Effect of Supplying Bile Acids on the Hepatic Levels of Triglycerides (A) and Cholesterol (B) and the Serum Levels of Triglycerides (C), Cholesterol (D) and Free Fatty Acids (E)

Each bar represents the mean \pm S.E.M. of 5 rats. ${ }^{*}$ Significantly different between the pairs indicated: $p<0.05$.

candidate endogenous AhR ligand. ${ }^{38)}$ Such attenuation in AhR ligand possibly produces a rise in abnormal morphology and liver function. However, an exogenous ligand, TCDD, probably produces hepatomegaly by activating another factor(s) such as inflammation enhancer in a food-independent fashion. ${ }^{39)}$ Although the definitive mechanism underlying TCDDinduced hepatotoxicity remains unclear, it is thought that the induction of oxidative stress ${ }^{40)}$ and inflammatory cytokines ${ }^{41)}$ are involved in this toxicity. In this context, the metabolomic analysis carried out in this study found that TCDD reduces the fecal content of $\alpha$-tocopherol and 6-keto-prostaglandin F1 $\alpha$, a stable metabolite of prostacyclin, and increases leukotriene (LT) A4, a precursor of LTB4, in the urine. Because prostacyclin and LTB4 are lipid mediators necessary for an inflammatory response, ${ }^{42,43)}$ these metabolomic changes seem to be the driving force for the induction of inflammation and oxidative stress producing hepatic injury. Further studies concerning the effect of dioxin on the hepatic metabolome are needed to clarify the relationship between hepatotoxicity and nutritional conditions.

The intestinal expression of ASBT was reduced by TCDD treatment. Because TCDD did not have any effect on the hepatic expression of BSEP and MRP2, it is suggested that one of the mechanisms underlying the elevated level of bile acids in the feces is attenuated resorption in the small intestine rather than excess release from the liver. Also, in accordance with a previous report ${ }^{25)}$ TCDD reduced or tended to reduce the hepatic expression of CYP7A1 and NTCP. CYP7A1 oxidizes cholesterol to its 7-hydroxy derivative, a rate-limiting step in bile acid synthesis, and NTCP is involved in the enterohepatic circulation of bile acids: that is, this protein transports bile acids back to the liver. ${ }^{26,44)}$ Therefore, these results suggest that TCDD disturbs bile acid homeostasis through a combination of defects in biosynthesis in the liver and a disturbance of enterohepatic circulation.

The expression of CYP7A1 and ASBT is regulated in a very complex fashion, and the mechanisms involved are not yet fully understood. It is well known that FXR binds with a high affinity to bile acids to induce the expression of SHP, a down-regulator for CYP7A1 and CYP8B1 ${ }^{45-48)}$ However, because the hepatic expression of FXR and SHP is reduced by TCDD treatment, it is unlikely that TCDD attenuates CYP7A1 owing to a change in the expression of these factors. In this context, a recent study has suggested that knocking-out LRH-1 gene suppresses the hepatic expression of CYP8B1, but not CYP7A1. ${ }^{47)}$ Taken these observations into consideration, it would be reasonable to believe that FXR-dependent regulation plays a greater role in the expression of CYP8B1 than CYP7A1, and a TCDD-induced reduction in FXR/SHP produces increased expression of CYP8B1. As mentioned above, TCDD induces inflammatory cytokines such as interleukin (IL) $-1 \beta$ and tumor necrosis factor $\alpha(\mathrm{TNF} \alpha)$ which cause liver damage. ${ }^{41)}$ Because both IL-1 $\beta$ and TNF $\alpha$ inhibit the expression of CYP7A1 ${ }^{49)}$ TCDD-produced inflammation may be one reason for the attenuated expression of CYP7A1. Mitro et al. have suggested that histone deacetylase (HDAC) suppresses the transcriptional activity of CYP7A $1^{50)}$ and our recent study has demonstrated that TCDD induces several isoforms of 
HDACs in the fetal pituitary. ${ }^{51)}$ Thus, an alternative possibility is that TCDD up-regulates hepatic HDACs to suppress hepatic CYP7A1.

Because circulating cholesterol has the ability to reduce the expression of ASBT, ${ }^{52,53)}$ a TCDD-produced increase in the serum level of cholesterol is assumed to be one of the mechanisms explaining an attenuation of this transporter. Also, the transcription of ASBT is stimulated through the activation of retinoic acid receptor/retinoid $\mathrm{X}$ receptor, ${ }^{54)}$ mitogen-activated protein kinase and epidermal growth factor. ${ }^{55}$ It is well known that dioxin reduces the hepatic level of retinol, ${ }^{2,56)}$ and the same was also observed in the feces in this study. Thus, further studies focusing on these forms of signaling will be needed for a better understanding of the mechanism(s) whereby ASBT is attenuated.

Cholesterol metabolism catalyzed by CYP7A1 and its scale is a major factor for determining cholesterol levels and maintaining lipid/steroid homeostasis. ${ }^{29,44)}$ In parallel with a TCDD-produced reduction in CYP7A1 expression, TCDD increased the serum content of cholesterol. Supplying cholic acid to TCDD-exposed rats caused a further reduction in the expression of CYP7A1, producing a concomitant increase in the cholesterol level. These results suggest that a TCDDproduced attenuation in the hepatic expression of CYP7A1 is a major reason why cholesterol homeostasis is disrupted by this dioxin. In this context, an FXR/SHP system is a biological sensor for the status of circulating cholesterol, ${ }^{29,44,45)}$ and the higher levels of cholesterol attenuate the expression of FXR to increase cholesterol metabolism. Taken together with our findings obtained in this study, it is reasonable to consider that TCDD initially targets the hepatic expression of CYP7A1 to reduce FXR/SHP and induce LRH-1, leading to the induction of CYP8B1 and/or a reduction in ASBT. The fact that supplying cholic acid attenuates the level of CYP8B1 mRNA suggests that a reduced circulation of this bile acid is one of the reasons for the CYP8B1 induction. In agreement with this, CYP8B1 is an important factor determining the ratio of cholic acid to chenodeoxycholic acid in the bile. ${ }^{57,58)}$ While a higher level of cholic acid decreases the expression of CYP8B1 to reduce the biosynthesis of cholic acid, this was not produced by an increase in chenodeoxycholic acid. ${ }^{58)}$

Neither treatment with TCDD nor cholates influenced the circulating level of free fatty acids. However, the assay kit used in this study was for the measurement of the total content of free fatty acids, and no information about changes in respective fatty acids could be obtained by this classical method. Our previous studies have revealed that 3,3',4,4',5-pentachlorobiphenyl, one of the toxic dioxins, produces a number of changes in the hepatic composition of fatty acids in rats. ${ }^{59,60)}$ Thus, it is highly likely that the circulation of some fatty acids is affected by TCDD treatment even if the apparent amount of total fatty acids does not exhibit any significant change. A further study focusing on the effect on each level of fatty acid will be important for a better understanding of the effect of TCDD on lipid homeostasis.

In conclusion, this study provides evidence that a TCDDinduced reduction in food consumption contributes to the metabolomic alterations in excrement. In addition, TCDD is suggested to facilitate the excretion of bile acids due to a reduction in ASBT and disrupts the biosynthesis of bile acids, leading to the impairment of bile acid and cholesterol homeostasis. Because such defects can be associated with the TCDD-produced disruption of lipid circulation, more studies focusing on the reduced circulation of bile acids are needed to clarify the toxic mechanism and its toxicological significance.

Acknowledgments This work was supported by Grants from the Japan Society for the Promotion of Science [Exploratory Research 24659053], and the Ministry of Health, Labour and Welfare of Japan [Research on Food Safety (H24-Designated Research-014)].

Conflict of Interest The authors declare no conflict of interest.

Supplementary Materials The online version of this article contains supplementary materials consisting of one table and four figures.

\section{REFERENCES}

1) Gasiewicz TA. 18.5 TCDD and other acnegenic materials. Handbook of Pesticide Toxicology (Hayes WJ Jr, Laws ER eds.) Vol. 3 Academic Press, San Diego, pp. 1217-1269 (1991).

2) Poland A, Knutson JC. 2,3,7,8-Tetrachlorodibenzo-p-dioxin and related halogenated aromatic hydrocarbons: examination of the mechanism of toxicity. Annu. Rev. Pharmacol. Toxicol., 22, 517-554 (1982).

3) Fernandez-Salguero PM, Hilbert DM, Rudikoff S, Ward JM, Gonzalez FJ. Aryl-hydrocarbon receptor-deficient mice are resistant to 2,3,7,8-tetrachlorodibenzo- $p$-dioxin-induced toxicity. Toxicol. Appl. Pharmacol., 140, 173-179 (1996).

4) Schmidt JV, Su GHT, Reddy JK, Simon MC, Bradfield CA. Characterization of a murine $\mathrm{Ahr}$ null allele: Involvement of the $\mathrm{Ah}$ receptor in hepatic growth and development. Proc. Natl. Acad. Sci. U.S.A., 93, 6731-6736 (1996).

5) Harrill JA, Hukkanen RR, Lawson M, Martin G, Gilger B, Soldatow V, Lecluyse EL, Budinsky RA, Rowlands JC, Thomas RS. Knockout of the aryl hydrocarbon receptor results in distinct hepatic and renal phenotypes in rats and mice. Toxicol. Appl. Pharmacol., 272, 503-518 (2013).

6) Fujisawa-Sehara A, Sogawa K, Yamane M, Fujii-Kuriyama Y. Characterization of xenobiotic responsive elements upstream from the drug-metabolizing cytochrome P-450c gene: a similarity to glucocorticoid regulatory elements. Nucleic Acids Res., 15, 4179-4191 (1987).

7) Mimura J, Fujii-Kuriyama Y. Functional role of AhR in the expression of toxic effects by TCDD. Biochim. Biophys. Acta, 1619, 263-268 (2003)

8) Frueh FW, Hayashibara KC, Brown PO, Whitlock JP Jr. Use of cDNA microarrays to analyze dioxin-induced changes in human liver gene expression. Toxicol. Lett., 122, 189-203 (2001)

9) Uno S, Dalton TP, Sinclair PR, Gorman N, Wang B, Smith AG, Miller ML, Shertzer HG, Nebert DW. Cypla1 $(-/-)$ male mice: protection against high-dose TCDD-induced lethality and wasting syndrome, and resistance to intrahepatocyte lipid accumulation and uroporphyria. Toxicol. Appl. Pharmacol., 196, 410-421 (2004).

10) Forgacs AL, Kent MN, Makley MK, Mets B, DelRaso N, Jahns GL, Burgoon LD, Zacharewski TR, Reo NV. Comparative metabolomic and genomic analyses of TCDD-elicited metabolic disruption in mouse and rat liver. Toxicol. Sci., 125, 41-55 (2012).

11) Berge P, Ratel J, Fournier A, Jondreville C, Feidt C, Roudaut B, Le Bizec B, Engel E. Use of volatile compound metabolic signatures in poultry liver to back-trace dietary exposure to rapidly metabolized xenobiotics. Environ. Sci. Technol., 45, 6584-6591 (2011). 
12) Lin S, Yang Z, Liu H, Cai Z. Metabolomic analysis of liver and skeletal muscle tissues in $\mathrm{C} 57 \mathrm{BL} / 6 \mathrm{~J}$ and $\mathrm{DBA} / 2 \mathrm{~J}$ mice exposed to 2,3,7,8-tetrachlorodibenzo-p-dioxin. Mol. Biosyst., 7, 1956-1965 (2011).

13) Lin S, Yang Z, Zhang X, Bian Z, Cai Z. Hippocampal metabolomics reveals 2,3,7,8-tetrachlorodibenzo- $p$-dioxin toxicity associated with ageing in Sprague-Dawley rats. Talanta, 85, 1007-1012 (2011).

14) Lin S, Kanawati B, Liu L, Witting M, Li M, Huang J, SchmittKopplin P, Cai Z. Ultrahigh resolution mass spectrometry-based metabolic characterization reveals cerebellum as a disturbed region in two animal models. Talanta, 118, 45-53 (2014).

15) Matsubara T, Tanaka N, Krausz KW, Manna SK, Kang DW, Anderson ER, Luecke H, Patterson AD, Shah YM, Gonzalez FJ. Metabolomics identifies an inflammatory cascade involved in dioxin- and diet-induced steatohepatitis. Cell Metab., 16, 634-644 (2012).

16) O'Kane AA, Chevallier OP, Graham SF, Elliott CT, Mooney MH. Metabolomic profiling of in vivo plasma responses to dioxinassociated dietary contaminant exposure in rats: implications for identification of sources of animal and human exposure. Environ. Sci. Technol., 47, 5409-5418 (2013).

17) Lu C, Wang Y, Sheng Z, Liu G, Fu Z, Zhao J, Zhao J, Yan X, Zhu B, Peng S. NMR-based metabonomic analysis of the hepatotoxicity induced by combined exposure to PCBs and TCDD in rats. Toxicol. Appl. Pharmacol., 248, 178-184 (2010).

18) Ruiz-Aracama A, Peijnenburg A, Kleinjans J, Jennen D, van Delft J, Hellfrisch C, Lommen A. An untargeted multi-technique metabolomics approach to studying intracellular metabolites of HepG2 cells exposed to 2,3,7,8-tetrachlorodibenzo- $p$-dioxin. BMC Genomics, 12, 251 (2011)

19) Matsumoto Y, Ishida T, Takeda T, Koga T, Fujii M, Ishii Y, Fujimura Y, Miura D, Wariishi H, Yamada H. Maternal exposure to dioxin reduces hypothalamic but not pituitary metabolome in fetal rats: a possible mechanism for a fetus-specific reduction in steroidogenesis. J. Toxicol. Sci., 35, 365-373 (2010).

20) Koga $T$, Ishida $T$, Takeda $T$, Ishii $Y$, Uchi H, Tsukimori K, Yamamoto M, Himeno M, Furue M, Yamada H. Restoration of dioxin-induced damage to fetal steroidogenesis and gonadotropin formation by maternal co-treatment with $\alpha$-lipoic acid. PLOS ONE, 7, e40322 (2012).

21) Greig JB, Jones G, Butler WH, Barnes JM. Toxic effects of 2,3,7,8-tetrachlorodibenzo- $p$-dioxin. Food Cosmet. Toxicol., 11, 585-595 (1973).

22) Harris MW, Moore JA, Vos JG, Gupta BN. General biological effects of TCDD in laboratory animals. Environ. Health Perspect., 5, 101-109 (1973).

23) Lindén J, Lensu S, Tuomisto J, Pohjanvirta R. Dioxins, the aryl hydrocarbon receptor and the central regulation of energy balance. Front. Neuroendocrinol., 31, 452-478 (2010).

24) Diani-Moore S, Zhang S, Ram P, Rifkind AB. Aryl hydrocarbon receptor activation by dioxin targets phosphoenolpyruvate carboxykinase (PEPCK) for ADP-ribosylation via 2,3,7,8-tetrachlorodibenzo- $p$-dioxin (TCDD)-inducible poly(ADP-ribose) polymerase (TiPARP). J. Biol. Chem., 288, 21514-21525 (2013).

25) Fletcher N, Wahlström D, Lundberg R, Nilsson CB, Nilsson KC, Stockling K, Hellmold H, Håkansson H. 2,3,7,8-Tetrachlorodibenzo- $p$-dioxin (TCDD) alters the mRNA expression of critical genes associated with cholesterol metabolism, bile acid biosynthesis, and bile transport in rat liver: a microarray study. Toxicol. Appl. Pharmacol., 207, 1-24 (2005).

26) Dawson AM. Bile salts and fat absorption. Gut, 8, 1-3 (1967).

27) Holt PR. The roles of bile acids during the process of normal fat and cholesterol absorption. Arch. Intern. Med., 130, 574-583 (1972).

28) Badley BW. Bile salts. Can. Med. Assoc. J., 102, 159-164 (1970).

29) Wilson JD. The role of bile acids in the overall regulation of steroid metabolism. Arch. Intern. Med., 130, 493-505 (1972).

30) Chiang JY. Bile acid metabolism and signaling. Compr. Physiol., 3,
1191-1212 (2013)

31) Takeda T, Fujii M, Hattori Y, Yamamoto M, Shimazoe T, Ishii $Y$, Himeno M, Yamada H. Maternal exposure to dioxin imprints sexual immaturity of the pups through fixing the status of the reduced expression of hypothalamic gonadotropin-releasing hormone. Mol. Pharmacol., 85, 74-82 (2014).

32) Schmittgen T, Livak KJ. Analyzing real-time PCR data by the comparative CT method. Nat. Protoc., 3, 1101-1108 (2008).

33) Huang M, Lee YS, Ho PC. Identification of circulatory and excretory metabolites of meisoindigo in rat plasma, urine and feces by high-performance liquid chromatography coupled with positive electrospray ionization tandem mass spectrometry. Rapid Commun. Mass Spectrom., 24, 729-741 (2010).

34) Trygg J, Holmes E, Lundstedt T. Chemometrics in metabonomics. $J$. Proteome Res., 6, 469-479 (2007).

35) Kakiyama G, Muto A, Takei H, Nittono H, Murai T, Kurosawa T, Hofmann AF, Pandak WM, Bajaj JS. A simple and accurate HPLC method for fecal bile acid profile in healthy and cirrhotic subjects: validation by GC-MS and LC-MS. J. Lipid Res., 55, 978-990 (2014)

36) Little RD. Histopathologic Technic. (Little RD ed.) The Blakiston Co., Philadelphia, pp. 156-176 (1949).

37) Harstad EB, Guite CA, Thomae TL, Bradfield CA. Liver deformation in Ahr-null mice: evidence for aberrant hepatic perfusion in early development. Mol. Pharmacol., 69, 1534-1541 (2006).

38) Opitz CA, Litzenburger UM, Sahm F, Ott M, Tritschler I, Trump S, Schumacher T, Jestaedt L, Schrenk D, Weller M, Jugold M, Guillemin GJ, Miller CL, Lutz C, Radlwimmer B, Lehmann I, von Deimling A, Wick W, Platten M. An endogenous tumour-promoting ligand of the human aryl hydrocarbon receptor. Nature, 478, 197203 (2011).

39) Slezak BP, Hatch GE, DeVito MJ, Diliberto JJ, Slade R, Crissman $\mathrm{K}$, Hassoun E, Birnbaum LS. Oxidative stress in female B6C3F1 mice following acute and subchronic exposure to 2,3,7,8-tetrachlorodibenzo-p-dioxin (TCDD). Toxicol. Sci., 54, 390-398 (2000).

40) Albro PW, Corbett JT, Harris M, Lawson LD. Effects of 2,3,7,8-tetrachlorodibenzo- $p$-dioxin on lipid profiles in tissue of the Fischer rat. Chem. Biol. Interact., 23, 315-330 (1978).

41) Fan F, Yan B, Wood G, Viluksela M, Rozman KK. Cytokines (IL-1 $\beta$ and TNF $\alpha$ ) in relation to biochemical and immunological effects of 2,3,7,8-tetrachlorodibenzo- $p$-dioxin (TCDD) in rats. Toxicology, 116, 9-16 (1997).

42) Ford-Hutchinson AW. Leukotriene B4 and neutrophil function: a review. J. R. Soc. Med., 74, 831-833 (1981).

43) Murata T, Ushikubi F, Matsuoka T, Hirata M, Yamasaki A, Sugimoto Y, Ichikawa A, Aze Y, Tanaka T, Yoshida N, Ueno A, Oh-ishi S, Narumiya S. Altered pain perception and inflammatory response in mice lacking prostacyclin receptor. Nature, 388, 678-682 (1997).

44) Russell DW, Setchell KD. Bile acid biosynthesis. Biochemistry, 31, 4737-4749 (1992)

45) Goodwin B, Jones SA, Price RR, Watson MA, Mckee DD, Moore LB, Galardi C, Wilson JG, Lewis MC, Roth ME, Maloney PR, Willson TM, Kliewer SA. A regulatory cascade of the nuclear receptors FXR, SHP-1, and LRH-1 represses bile acid biosynthesis. Mol. Cell, 6, 517-526 (2000).

46) Lew JL, Zhao A, Yu J, Huang L, De Pedro N, Peláez F, Wright $\mathrm{SD}$, Cui J. The farnesoid $\mathrm{X}$ receptor controls gene expression in a ligand- and promoter-selective fashion. J. Biol. Chem., 279, 88568861 (2004)

47) Lee YK, Schmidt DR, Cummins CL, Choi M, Peng L, Zhang Y, Goodwin B, Hammer RE, Mangelsdorf DJ, Kliewer SA. Liver receptor homolog-1 regulates bile acid homeostasis but is not essential for feedback regulation of bile acid synthesis. Mol. Endocrinol., 22, 1345-1356 (2008).

48) Chiang JY. Bile acids: regulation of synthesis. J. Lipid Res., 50, 1955-1966 (2009). 
49) Li T, Jahan A, Chiang JY. Bile acids and cytokines inhibit the human cholesterol 7 alpha-hydroxylase gene via the JNK/c-jun pathway in human liver cells. Hepatology, 43, 1202-1210 (2006).

50) Mitro N, Godio C, De Fabiani E, Scotti E, Galmozzi A, Gilardi F, Caruso D, Vigil Chacon AB, Crestani M. Insights in the regulation of cholesterol 7alpha-hydroxylase gene reveal a target for modulating bile acid synthesis. Hepatology, 46, 885-897 (2007).

51) Takeda T, Fujii M, Taura J, Ishii Y, Yamada H. Dioxin silences gonadotropin expression in perinatal pups by inducing histone deacetylases: a new insight into the mechanism for the imprinting of sexual immaturity by dioxin. J. Biol. Chem., 287, 18440-18450 (2012).

52) Alrefai WA, Sarwar Z, Tyagi S, Saksena S, Dudeja PK, Gill RK. Cholesterol modulates human intestinal sodium-dependent bile acid transporter. Am. J. Physiol. Gastrointest. Liver Physiol., 288, G978-G985 (2005).

53) Thomas C, Landrier JF, Gaillard D, Grober J, Monnot MC, Athias A, Besnard P. Cholesterol dependent downregulation of mouse and human apical sodium dependent bile acid transporter (ASBT) gene expression: molecular mechanism and physiological consequences. Gut, 55, 1321-1331 (2006).
54) Neimark E, Chen F, Li X, Shneider BL. Bile acid-induced negative feedback regulation of the human ileal bile acid transporter. Hepatology, 40, 149-156 (2004).

55) Duane WC, Xiong W, Wolvers J. Effects of bile acids on expression of the human apical sodium dependent bile acid transporter gene. Biochim. Biophys. Acta, 1771, 1380-1388 (2007).

56) Thunberg T, Ahlborg UG, Johnsson H. Vitamin A (retinol) status in the rat after a single oral dose of 2,3,7,8-tetrachlorodibenzo- $p$ dioxin. Arch. Toxicol., 42, 265-274 (1979).

57) Chiang JY. Regulation of bile acid synthesis. Front. Biosci., 3, d176-d193 (1998).

58) Vlahcevic ZR, Eggertsen G, Bjorkhem I, Hylemon PB, Redford K, Pandak WM. Regulation of sterol $12 \alpha$-hydroxylase and cholic acid biosynthesis in the rat. Gastroenterology, 118, 599-607 (2000).

59) Matsusue K, Ishii Y, Ariyoshi N, Oguri K. A highly toxic PCB produces unusual changes in the fatty acid composition of rat liver. Toxicol. Lett., 91, 99-104 (1997).

60) Matsusue K, Ishii Y, Ariyoshi N, Oguri K. A highly toxic coplanar polychlorinated biphenyl compound suppresses Delta5 and Delta6 desaturase activities which play key roles in arachidonic acid synthesis in rat liver. Chem. Res. Toxicol., 12, 1158-1165 (1999). 